\title{
Effects of reflow profile and thermal conditioning on intermetallic compound thickness for SnAgCu soldered joints
}

\author{
Fianbiao Pan \\ Department of Industrial and Manufacturing Engineering, \\ California Polytechnic State University, San Luis Obispo, California, USA \\ Tzu-Chien Chou \\ IBM Taiwan, Taipei, Taiwan \\ Fasbir Bath \\ Bath Technical Consultancy, Fremont, California, USA \\ Dennis Willie \\ Flextronics International, San Jose, California, USA, and \\ Brian F. Toleno \\ Henkel Technologies, Irvine, California, USA
}

\begin{abstract}
Purpose - The purpose of this paper is to investigate the effects of reflow time, reflow peak temperature, thermal shock and thermal aging on the intermetallic compound (IMC) thickness for Sn3.0Ag0.5Cu (SAC305) soldered joints.

Design/methodology/approach - A four-factor factorial design with three replications is selected in the experiment. The input variables are the peak temperature, the duration of time above solder liquidus temperature (TAL), solder alloy and thermal shock. The peak temperature has three levels, 12 , 22 and $32^{\circ} \mathrm{C}$ above solder liquidus temperatures (or 230,240 and $250^{\circ} \mathrm{C}$ for SAC305 and 195, 205, and $215^{\circ} \mathrm{C}$ for SnPb). The TAL has two levels, 30 and $90 \mathrm{~s}$. The thermally shocked test vehicles are subjected to air-to-air thermal shock conditioning from -40 to $125^{\circ} \mathrm{C}$ with $30 \mathrm{~min}$ dwell times (or $1 \mathrm{~h} /$ cycle) for 500 cycles. Samples both from the initial time zero and after thermal shock are cross-sectioned. The IMC thickness is measured using scanning electron microscopy. Statistical analyses are conducted to compare the difference in IMC thickness growth between SAC305 solder joints and SnPb solder joints, and the difference in IMC thickness growth between after thermal shock and after thermal aging.

Findings - The IMC thickness increases with higher reflow peak temperature and longer time above liquidus. The IMC layer of SAC305 soldered joints is statistically significantly thicker than that of $\mathrm{SnPb}$ soldered joints when reflowed at comparable peak temperatures above liquidus and the same time above liquidus. Thermal conditioning leads to a smoother and thicker IMC layer. Thermal shock contributes to IMC growth merely through hightemperature conditioning. The IMC thickness increases in SAC305 soldered joints after thermal shock or thermal aging are generally in agreement with prediction models such as that proposed by Hwang.

Research limitations/implications - It is still unknown which thickness of IMC layer could result in damage to the solder.

Practical implications - The IMC thickness of all samples is below $3 \mu \mathrm{m}$ for both SnPb and SAC305 solder joints reflowed at the peak temperature ranging from 12 to $32^{\circ} \mathrm{C}$ above liquidus temperature and at times above liquidus ranging from 30 to $90 \mathrm{~s}$. The IMC thickness is below $4 \mu \mathrm{m}$ after subjecting to air-to-air thermal shock from -40 to $125^{\circ} \mathrm{C}$ with 30 min dwell time for 500 cycles or thermal aging at $125^{\circ} \mathrm{C}$ for $250 \mathrm{~h}$.

Originality/value - The paper reports experimental results of IMC thickness at different thermal conditions. The application is useful for understanding the thickness growth of the IMC layer at various thermal conditions.
\end{abstract}

Keywords Thermal properties of materials, Soldering, Solders, Alloys

This work was partly sponsored by the Department of the Navy, Office of Naval Research, under Award No. N00014-05-1-0855. The authors would also like to thank Charlson Bernal, Roger Jay, Teresita Villavert, Mark Elkins, and Mike Lamb of Flextronics International for assistance in SEM analysis. 


\section{Introduction}

Long-term reliability of solder interconnections depends on intermetallic compound (IMC) formation (Miric and Grusd, 1998). The IMC is necessary for a good solder interconnection and its presence gives a bonding layer between the bulk solder and component termination and/or board substrates. Solder joint reliability can be affected by both lack of an IMC layer and too thick an IMC layer. If a thick IMC layer was formed within the solder joint, its brittleness can cause solder joint reliability concerns.

There are many factors that affect the degree of IMC formation during the soldering process. Harris and Chaggar (1998) concluded that the quantity of IMC is a direct function of the soldering time and temperature. During the reflow process, the base metal such as copper $(\mathrm{Cu})$ which is the most widely used, dissolves into the molten solder and forms the IMC layer at the interface. Although the roles of reflow profile on $\mathrm{SnPb}$ solder joint performance have been well studied (Lee, 1999, 2002), its effect on lead-free soldered joints are not yet fully understood. Fairly recently, reflow profile studies focused on shear strength performance and microstructural characterization (Yang et al., 1995; Bukhari et al., 2005; Oliver et al., 2002; Pan et al., 2006; Webster et al., 2007), with only very limited studies on the IMC layer thickness (Salam et al., 2004).

The reflow peak temperature and the time above liquidus are two critical variables in determining the IMC thickness (Harris and Chaggar, 1998; Salam et al., 2004). It is well known that the liquidus temperatures of lead-free alloys are higher than that of eutectic $\mathrm{SnPb}$ alloy. The liquidus temperature of $\mathrm{Sn} 3.8 \mathrm{Ag} 0.7 \mathrm{Cu}$ and $\mathrm{Sn} 3.0 \mathrm{Ag} 0.5 \mathrm{Cu}$ are between 217 and $219^{\circ} \mathrm{C}$, which is $34-36^{\circ} \mathrm{C}$ higher than for eutectic $\mathrm{SnPb}$ solder. Since the rate of dissolution of the base material in the molten alloy is faster as the temperature increases, it is expected that a thicker IMC layer will form at a higher reflow peak temperature. However, Roubaud and Henshall (2001) found that the higher lead-free solder reflow temperature $\left(250^{\circ} \mathrm{C}\right)$ did not lead to a significantly higher thickness of IMC layer between the bulk solder and the copper substrate in lead-free assemblies. Arra et al. (2002) concluded that the IMC layer thickness between the solder and the substrate did not change significantly with the different reflow profiles tested, although the IMC layer thickness between the solder and the component with both 100 per cent $\mathrm{Sn}$ and $\mathrm{SnPb}$ coatings was found to increase with the higher peak temperature or the longer time above liquidus.

Thermal aging can cause IMC growth as well. For example, Salam et al. reported that the IMC thickness of $\mathrm{SnAgCu}$ soldered joints increased from 1-2.5 to 3-4.5 $\mu \mathrm{m}$ after aging at $150^{\circ} \mathrm{C}$ for $300 \mathrm{~h}$ (Salam et al., 2004). Harris and Chaggar (1998) further indicated that the rate of intermetallic growth in the solid state was slower for the high-melting point leadfree alloys than for conventional tin-lead formulations.

The objective of this study was to investigate the effect of reflow profile and thermal shock on the solder joint shear strength and IMC thickness. The effect of reflow profile on the solder joint shear strength was reported by Pan et al. (2006). The effect of thermal shock on the solder joint shear strength has also been presented (Webster et al., 2007). This paper reports the effect of reflow profile and thermal shock on the IMC thickness for $\mathrm{Sn3} .0 \mathrm{Ag} 0.5 \mathrm{Cu}$ alloy.

\section{Experimental design and procedures}

A four-factor factorial design with three replications was selected in the experiment. The input variables were the peak temperature, the duration of time above solder liquidus temperature or TAL, solder alloy, and thermal shock. The peak temperature has three levels: 12,22 and $32^{\circ} \mathrm{C}$ above solder liquidus temperatures (or 230,240 and $250^{\circ} \mathrm{C}$ for SAC305 and 195, 205 and $215^{\circ} \mathrm{C}$ for $\mathrm{SnPb}$ ). The TAL has two levels, 30 and $90 \mathrm{~s}$. Therefore, there are six reflow profiles for eutectic $\mathrm{SnPb}$ solder and six for SAC305 solder. Test boards were assembled with four different sizes of pure tin plated surface mount chip resistors (0402, 0603, 0805 and 1206). The board finish of the test vehicles was organic solderability preservative (OSP). There were 14 of each resistor size on each board, or 56 components in total per board as shown in Figure 1. Three boards were assembled for each experimental run, so a total of 54 boards were assembled (three peak temperatures $\times$ three TAL $\times$ two solder alloys $\times$ three replications). The experimental matrix is listed in Table I. A $0.1 \mathrm{~mm}$ (4 mil) thick laser-cut electro-polished stencil with a 1:1 stencil aperture to pad ratio was used. Both $\mathrm{SnPb}$ and SAC305 pastes were Type 3 with no-clean flux. The reflow oven processing was done in air.

Figure 1 Test vehicle

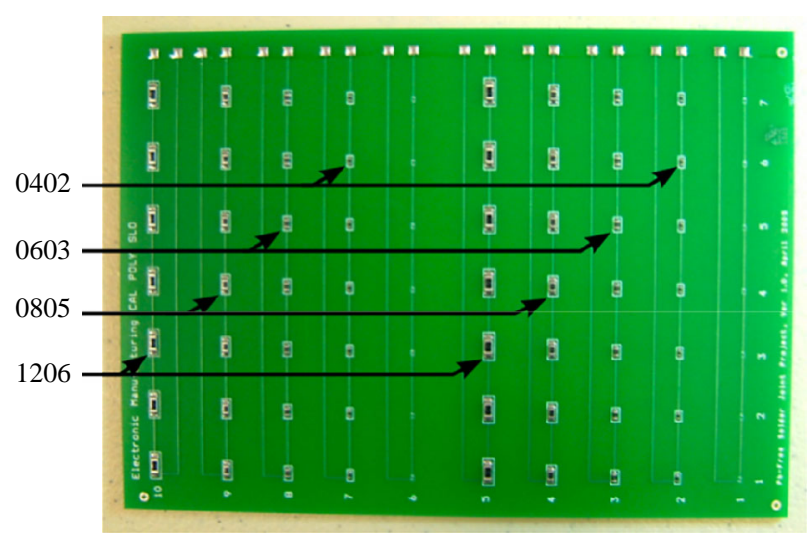

Table I Experiment matrix

\begin{tabular}{llll}
\hline Factors & $\mathbf{2}$ & Levels \\
\hline $\begin{array}{l}\text { Peak temperature } \\
\text { above solder liquidus }\end{array}$ & & $\mathbf{2}$ \\
$\begin{array}{l}\text { temperature }\left({ }^{\circ} \mathrm{C}\right) \\
\text { TAL }(\mathbf{s})\end{array}$ & 12 & 22 & 32 \\
Solder alloy & 30 & 90 & \\
Thermal shock & $\mathrm{SnPb}$ & $\mathrm{SAC} 305$ \\
& No thermal & $\begin{array}{l}\text { After thermal } \\
\text { shock }\end{array}$ & shock from \\
& & -40 to $125^{\circ} \mathrm{C}$ \\
& & with 30 min \\
& & dwell times \\
& & (or $1 \mathrm{~h} /$ cycle) \\
& & for 500 cycles \\
\hline
\end{tabular}


Each board was cut into two identical pieces. The first half of the board was for the initial time zero evaluation after assembly and the components on the other half of the board were thermally shocked after assembly. The thermally shocked test vehicles were subjected to air-to-air thermal shock conditioning from -40 to $125^{\circ} \mathrm{C}$ with $30 \mathrm{~min}$ dwell times (or $1 \mathrm{~h} /$ cycle) for 500 cycles.

Samples both from the initial time zero and after thermal shock were cross-sectioned to measure the IMC thickness. The samples were encapsulated in a mixture of epoxy resin and hardener. Care was taken during grinding to not put excessive pressure on the sample to prevent the different metal layers being smeared. The grit size started from 120 , following by the number $320,600,800,1,200,2,400$ and 4,000. For each grit size, the technique was to hold the sample in one direction with a scratch pattern opposite to the previous one. The samples were then fine polished using 0.3 and $0.05 \mu \mathrm{m}$ alumina slurries. For the fine polishing steps, the samples were rotated against the wheel rotation. The last steps were etching with a 50-50 concentration of $\mathrm{NH}_{4} \mathrm{OH}$ and $\mathrm{H}_{2} \mathrm{O}_{2}$ and sputter coating with approximately $100 \mathrm{~A}$ of platinum.

The IMC thickness was measured using scanning electron microscopy $($ SEM) at $5000 \times$ magnification with energy dispersive spectroscopy. To keep consistency, only the 0603 resistor from each reflow profile was cut out for IMC thickness measurement. Although, the IMC formed at both the board pad and component terminal side of the solder joint, only the IMC layer at the board side was measured. This was because the IMC layer on the component side usually was very thin and not easy to distinguish for measurements. Figure 2 shows a sample image of a cross-sectioned sample. Since the IMC layer thickness is not uniform as shown in the right side of Figure 2, four or five measurements were taken at different locations of the cross-section along the solder/Cu interface and the average value of the IMC thickness was used for analysis.

\section{Results and discussion}

IMC thickness vs reflow profile

The IMC thicknesses of SAC305 soldered joints for different reflow profiles are summarized in Table II. Figure 3 shows that the SAC305 solder joint IMC thickness before thermal shock increased as the peak temperature and the time above liquidus increased. It indicates that the dissolution rate of $\mathrm{Cu}$ into the molten solder is higher at a high-reflow peak temperature. However, the increase in IMC thickness is not linear with the peak temperature.

IMC thickness vs thermal shock and thermal aging IMC thickness comparisons before and after thermal shock from -40 to $125^{\circ} \mathrm{C}$ for 500 cycles are shown in Figure 3. All the samples after thermal shock appeared to have a noticeable increase in IMC thickness.

Hwang (2001) presented an IMC growth model as shown below:

$$
X=X_{0}+1.78 \times 10^{-2} t^{0.52} e^{(-57,700 / R T)}
$$

where $\mathrm{X}$ is the total IMC thickness in meters after thermal aging for a time $t$ in seconds; $X_{0}$ is the initial IMC thickness before thermal aging; $\mathrm{R}$ is the gas constant, which is equal to $8.314 \mathrm{~J} / \mathrm{mol} \mathrm{K}$; and $\mathrm{T}$ is the temperature in Kelvins. The IMC thickness increase for SAC305 joints after thermal shock from -40 to $+125^{\circ} \mathrm{C}$ with a dwell time of $30 \mathrm{~min}$ for 500 cycles can be calculated as:

$$
\begin{aligned}
\delta X= & X-X_{0}=1.78 \times 10^{-2} t^{0.52} e^{(-57,700 / R T)} \\
= & 1.78 \times 10^{-2} \times(250 \times 60 \times 60)^{0.52} \\
& \times e^{(-57,700 /(8.314 \times(125+273)))}+1.78 \times 10^{-2} \\
& \times(250 \times 60 \times 60)^{0.52} e^{(-57,700 /(8.314 \times(-40+273)))} \\
= & 0.59 \times 10^{-6} \mathrm{~m} \text { or } 0.59 \mu \mathrm{m}
\end{aligned}
$$

Equation (1) indicates that the rate of IMC formation at $-40^{\circ} \mathrm{C}$ is very low and can be ignored. To find out whether thermal shock merely contributed to IMC growth through high-temperature conditioning and verify whether Hwang's model was correct, we did an experiment. About 12 boards which had not been subjected to thermal shock in the previous experiment were selected, two boards each that were subjected to reflow conditions at $230^{\circ} \mathrm{C}$ for $30 \mathrm{~s}, 240^{\circ} \mathrm{C}$ for $30 \mathrm{~s}, 250^{\circ} \mathrm{C}$ for $30 \mathrm{~s}, 230^{\circ} \mathrm{C}$ for $90 \mathrm{~s}, 240^{\circ} \mathrm{C}$ for $90 \mathrm{~s}, 250^{\circ} \mathrm{C}$ for

Figure 2 Cross-section sample of a 0603 chip component

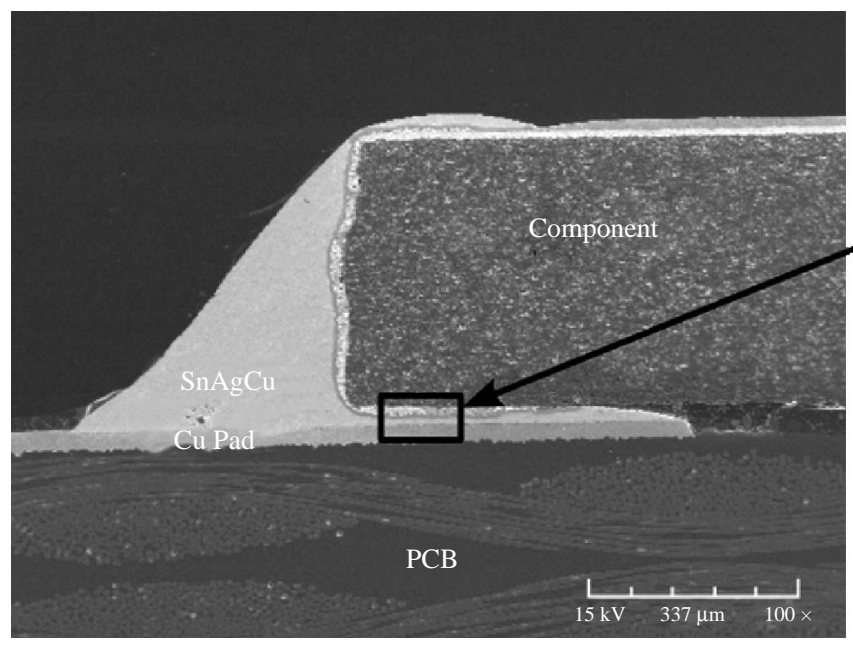

(a)

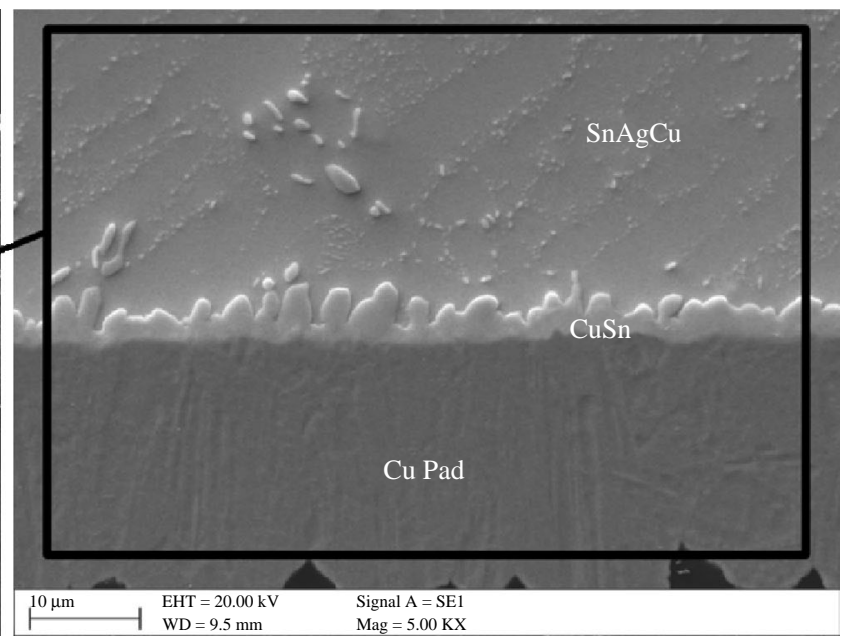

(b)

Notes: (a) With a magnification of $100 \times$; (b) with a magnification of $5,000 \times$ 
Table II IMC thickness of SAC305 soldered joints on OSP/Cu board for different reflow profiles

\begin{tabular}{|c|c|c|c|c|c|}
\hline \multicolumn{2}{|c|}{ Reflow profile } & \multicolumn{4}{|c|}{ IMC thickness $(\mu \mathrm{m})$} \\
\hline \multirow{2}{*}{$\begin{array}{l}\text { Peak } \\
\text { temperature } \\
\left({ }^{\circ} \mathrm{C}\right)\end{array}$} & \multirow{2}{*}{$\begin{array}{l}\text { Time } \\
\text { above } \\
\text { liquidus } \\
\text { (s) }\end{array}$} & \multicolumn{2}{|c|}{$\begin{array}{l}\text { Before } \\
\text { thermal } \\
\text { shock }\end{array}$} & \multicolumn{2}{|c|}{$\begin{array}{l}\text { After } \\
\text { thermal } \\
\text { shock }\end{array}$} \\
\hline & & Mean & SD & Mean & SD \\
\hline \multirow[t]{2}{*}{230} & 30 & 1.12 & 0.04 & 1.88 & 0.12 \\
\hline & 90 & 1.14 & 0.15 & 1.83 & 0.18 \\
\hline \multirow[t]{2}{*}{240} & 30 & 1.45 & 0.03 & 1.87 & 0.54 \\
\hline & 90 & 1.90 & 0.14 & 2.47 & 0.42 \\
\hline \multirow[t]{2}{*}{250} & 30 & 1.43 & 0.08 & 1.97 & 0.38 \\
\hline & 90 & 1.91 & 0.14 & 2.17 & 0.51 \\
\hline
\end{tabular}

Figure 3 IMC thickness comparison before and after thermal shock

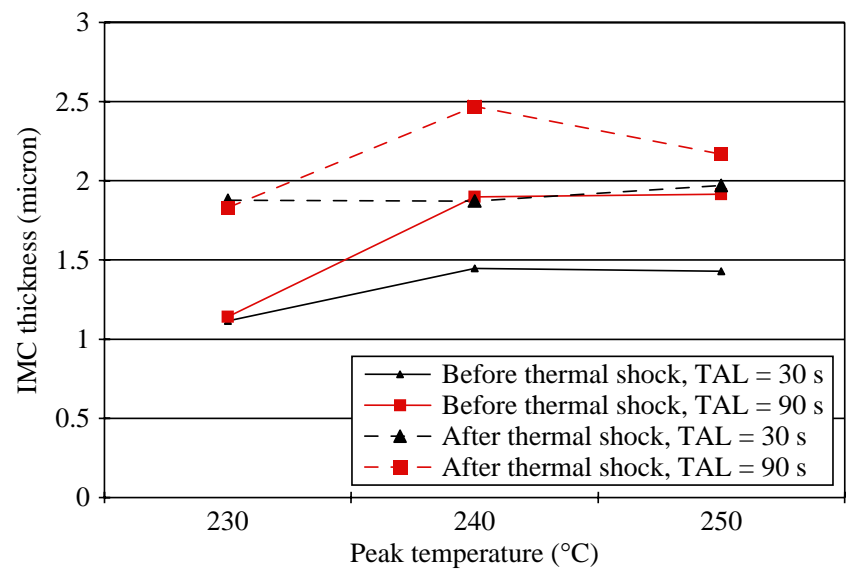

90 s, respectively. One board from each reflow condition was sent for thermal aging at $+125^{\circ} \mathrm{C}$ for $250 \mathrm{~h}$ and the other board, without thermal aging, was used as a control. The thermal aging condition was the same as the high-temperature conditioning of the thermal shock used in this study. One 0603 component from the twelve boards was cross-sectioned and the IMC thickness was measured using SEM. The IMC thickness is summarized in Table III.

To test the hypothesis that thermal shock merely contributed to IMC growth through high-temperature conditioning, the IMC thickness growth resulted from the thermal shock and the thermal aging was compared using student's $t$-test. The null and alternative hypotheses are:

$$
\begin{aligned}
H_{0} & : \mu_{\text {thermal_shock }}=\mu_{\text {thermal_aging }} \text { versus } H_{1}: \mu_{\text {thermal_shock }} \\
& \neq \mu_{\text {thermal_aging }}
\end{aligned}
$$

where $\mu_{\text {thermal_shock }}$ is the mean IMC thickness growth after thermal shock and $\mu_{\text {thermal_aging }}$ is the mean IMC thickness growth after thermal aging. The calculated $p$-value is 0.51 and the 95 per cent confidence interval for the difference ( $\left.\mu_{\text {thermal_shock }}-\mu_{\text {thermal_aging }}\right)$ is $(-0.25,0.39)$. Since the $p$-value is 0.51 , larger than 0.05 , we do not reject the null hypothesis at 95 per cent confidence level. Thus, the data did not show statistically significant difference in IMC thickness growth between the thermal shock from -40 to $125^{\circ} \mathrm{C}$ for
500 cycles and the thermal aging at $125^{\circ} \mathrm{C}$ for $250 \mathrm{~h}$. Though we cannot conclude that the null hypothesis is true, this result indicates that thermal shock contributes to IMC growth merely through high-temperature conditioning.

To test whether the average IMC growth after thermal shock or after thermal aging matches the calculated IMC thickness change from Hwang's model, another hypothesis test was performed. The six data of the IMC growth after thermal shock from -40 to $125^{\circ} \mathrm{C}$ for 500 cycles have a mean of $0.54 \mu \mathrm{m}$ and standard deviation of 0.181 . The six data of IMC growth after thermal aging at $125^{\circ} \mathrm{C}$ for $250 \mathrm{~h}$ have a mean of $0.47 \mu \mathrm{m}$ and standard deviation of 0.282 . IMC thickness growth calculated from Hwang's model is $0.59 \mu \mathrm{m}$. The null and alternative hypotheses are:

$$
\begin{aligned}
& H_{0}: \mu_{\text {thermal_shock }}=0.59 \text { versus } H_{1}: \mu_{\text {thermal_shock }} \neq 0.59 \\
& H_{0}: \mu_{\text {thermal_aging }}=0.59 \text { versus } H_{1}: \mu_{\text {thermal_aging }} \neq 0.59
\end{aligned}
$$

The calculated $p$-value for the thermal shock case is 0.53 and the $p$-value for the thermal aging case is 0.35 . Both are significantly larger than 0.05 . Thus, we fail to reject the null hypothesis and can conclude that the IMC thickness growth of SAC305 soldered joints after thermal conditioning is generally in agreement with Hwang's model.

It is noted that the IMC layer becomes smoother after thermal aging than before thermal aging. Figure 4 shows a SEM picture before thermal aging and Figure 5 is a SEM picture after thermal ageing; both samples were reflowed at $230^{\circ} \mathrm{C}$ for $30 \mathrm{~s}$. This phenomenon is consistent for all 12 samples. The phenomenon of the interfacial morphology becaming smoother as the thermal cycles increased was also reported by Chen et al. (2006).

Another point was that the IMC thickness was below $4 \mu \mathrm{m}$ after being subjected to air-to-air thermal shock from -40 to $125^{\circ} \mathrm{C}$ with a $30 \mathrm{~min}$ dwell time for 500 cycles or thermal aging at $125^{\circ} \mathrm{C}$ for $250 \mathrm{~h}$. That IMC thickness is generally considered to be acceptable within the industry. Though the shear strength of solder joints degraded significantly after thermal shock (Webster et al., 2007), no IMC failure was observed after shear tests. This indicates that the degradation in shear strength after thermal shock was due to the microstructural change in the bulk solder joints since the fracture interface was in the bulk solder and/or component metallization, not in the IMC layer.

\section{IMC thickness vs solder alloy}

The IMC thicknesses of $\mathrm{SnPb}$ and SAC305 soldered joints are compared in Table IV. A paired $t$-test was carried out to test the hypothesis that the IMC of SAC305 solder joints is thicker than that of $\mathrm{SnPb}$ solder joints when reflowed at comparable peak temperatures above liquidus and the same time above liquidus. The null and alternative hypotheses are:

$$
H_{0}: \mu_{\mathrm{SAC} 305}=\mu_{\mathrm{SnPb}} \text { versus } H_{1}: \mu_{\mathrm{SAC} 305}>\mu_{\mathrm{SnPb}}
$$

where $\mu_{\mathrm{SAC} 305}$ is the mean IMC thickness of SAC305 solder joints, and $\mu_{\mathrm{SnPb}}$ is the mean IMC thickness of $\mathrm{SnPb}$ solder joints. The calculated $p$-value is 0.049 , which is less than 0.05 . Thus, we reject the null hypothesis and conclude that the IMC of SAC305 solder joints is thicker than that of $\mathrm{SnPb}$ solder joints when reflowed at comparable peak temperatures above liquidus and the same time above liquidus. This result could be explained by the fact that the copper dissolved faster 
Table III IMC Thickness of SAC305 solder joints on OSP/Cu board before and after thermal treatment

\begin{tabular}{|c|c|c|c|c|c|c|c|}
\hline \multirow{2}{*}{\multicolumn{2}{|c|}{ Reflow profile }} & \multicolumn{6}{|c|}{ Average IMC thickness $(\mu \mathrm{m})$} \\
\hline & & \multicolumn{3}{|c|}{ Thermal shock from -40 to $125^{\circ} \mathrm{C}$ for 500 cycles } & \multicolumn{3}{|c|}{ Thermal aging at $125^{\circ} \mathrm{C}$ for $250 \mathrm{~h}$} \\
\hline Peak temperature $\left({ }^{\circ} \mathrm{C}\right)$ & Time above liquidus (s) & Before & After & IMC thickness increase & Before & After & IMC thickness increase \\
\hline \multirow[t]{2}{*}{230} & 30 & 1.12 & 1.88 & 0.76 & 1.12 & 1.52 & 0.40 \\
\hline & 90 & 1.14 & 1.83 & 0.69 & 1.96 & 2.07 & 0.12 \\
\hline \multirow[t]{2}{*}{240} & 30 & 1.45 & 1.87 & 0.42 & 1.50 & 1.90 & 0.41 \\
\hline & 90 & 1.90 & 2.47 & 0.57 & 2.10 & 2.96 & 0.86 \\
\hline \multirow[t]{2}{*}{250} & 30 & 1.43 & 1.97 & 0.54 & 1.35 & 2.10 & 0.75 \\
\hline & 90 & 1.91 & 2.17 & 0.26 & 3.41 & 3.69 & 0.28 \\
\hline
\end{tabular}

Figure 4 A SEM image of a sample reflowed at $230^{\circ} \mathrm{C}$ for $30 \mathrm{~s}$, before thermal aging

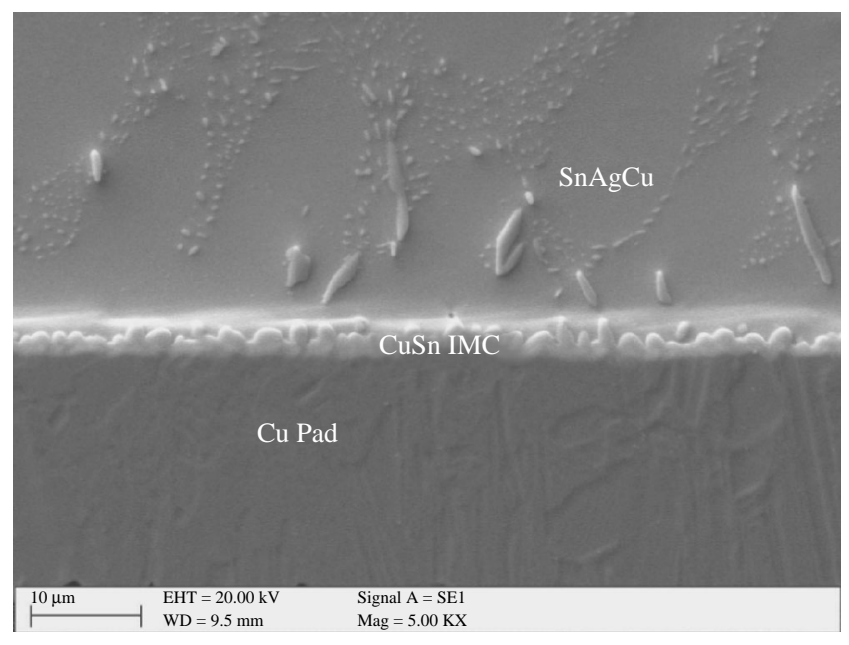

Figure 5 A SEM image of a sample reflowed at $230^{\circ} \mathrm{C}$ for $30 \mathrm{~s}$, after thermal ageing

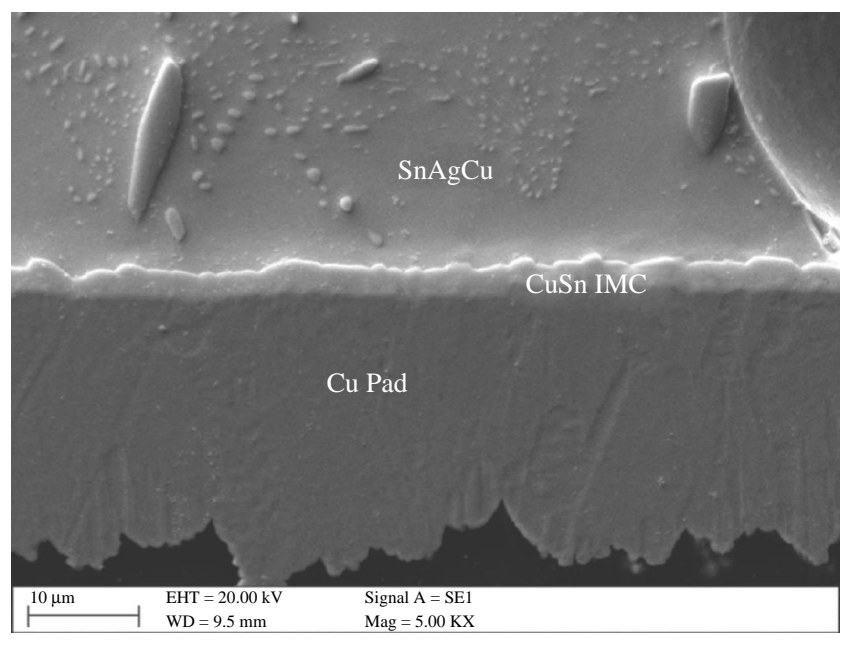

at the high-reflow temperature and there is a higher tin content in the $96.5 \mathrm{Sn} 3 \mathrm{Ag} 0.5 \mathrm{Cu}$ alloy compared with $63 \mathrm{Sn} 37 \mathrm{~Pb}$, which results in more IMC formation.

\section{Conclusions}

A systematic study on the effects of reflow profile (peak temperature and time above liquidus) and thermal
Table IV IMC thickness comparison between SAC305 soldered joints and $\mathrm{SnPb}$ soldered joints

\begin{tabular}{|c|c|c|c|c|c|}
\hline \multicolumn{2}{|c|}{ Reflow profile } & \multicolumn{4}{|c|}{ IMC thickness $(\mu \mathrm{m})$} \\
\hline \multirow{2}{*}{$\begin{array}{l}\text { Peak } \\
\text { temperature above } \\
\text { liquidus }\left({ }^{\circ} \mathrm{C}\right)\end{array}$} & \multirow{2}{*}{$\begin{array}{l}\text { Time above } \\
\text { liquidus (s) }\end{array}$} & \multicolumn{2}{|c|}{$\begin{array}{l}\text { SnPb solder } \\
\text { joints }\end{array}$} & \multicolumn{2}{|c|}{$\begin{array}{c}\text { SAC305 } \\
\text { solder joints }\end{array}$} \\
\hline & & Mean & SD & Mean & SD \\
\hline \multirow[t]{2}{*}{12} & 30 & 0.95 & 0.10 & 1.12 & 0.04 \\
\hline & 90 & 1.23 & 0.10 & 1.14 & 0.15 \\
\hline 22 & 60 & 1.17 & 0.10 & 1.29 & 0.10 \\
\hline \multirow[t]{2}{*}{32} & 30 & 1.05 & 0.08 & 1.43 & 0.08 \\
\hline & 90 & 1.49 & 0.11 & 1.91 & 0.14 \\
\hline
\end{tabular}

conditioning on the intermetallic layer growth was conducted. The IMC thickness of both $\mathrm{SnPb}$ and SAC305 soldered joints under different reflow profiles was compared. The IMC thickness of all samples was below $3 \mu \mathrm{m}$ for both $\mathrm{SnPb}$ and SAC305 solder joints reflowed at peak temperatures ranging from 12 to $32^{\circ} \mathrm{C}$ above liquidus temperature and times above liquidus ranging from 30 to $90 \mathrm{~s}$. The IMC thickness was below $4 \mu \mathrm{m}$ after being subjected to air-to-air thermal shock from -40 to $125^{\circ} \mathrm{C}$ with a $30 \mathrm{~min}$ dwell time for 500 cycles or thermal aging at $125^{\circ} \mathrm{C}$ for $250 \mathrm{~h}$. Up to $4 \mu \mathrm{m}$ of IMC thickness is generally considered to be acceptable within the electronics industry. However, it is still unknown how thick an IMC layer would result in damage of solder joints.

The IMC thickness increased as the peak temperature and the time above liquidus increased. However, the increase of IMC thickness was not linear with the peak temperature. Statistical analysis demonstrates that the IMC of SAC305 soldered joints was thicker than that of $\mathrm{SnPb}$ soldered joints for the same comparable peak temperature above liquidus and for the same time above liquidus at 95 per cent confidence level.

Thermal shock leads to a thicker and smoother IMC layer. Statistical analysis shows that there is not a significant difference in IMC thickness growth between the thermal shock from -40 to $125^{\circ} \mathrm{C}$ for 500 cycles and the thermal aging at $125^{\circ} \mathrm{C}$ for $250 \mathrm{~h}$. This indicates that thermal shock contributes to IMC growth merely through high-temperature conditioning. The IMC thickness growth of SAC305 soldered joints after thermal shock or thermal aging is generally in agreement with Hwang's model. 


\section{References}

Arra, M., Shangguan, D., Ristolainen, E. and Lepisto, T. (2002), "Effect of reflow profile on wetting and intermetallic formation between $\mathrm{Sn} / \mathrm{Ag} / \mathrm{Cu}$ solder components and printed circuit boards", Soldering \& Surface Mount Technology, Vol. 14 No. 2, pp. 18-25.

Bukhari, B., Santos, D.L., Lehman, L.P. and Cotts, E. (2005), "Continued evaluation of the effects of processing conditions and aging treatments on shear strength and microstructure in $\mathrm{Pb}$-free surface mount assembly", Proceedings of the SMTA Pan Pacific Microelectronics Symposium, Chicago, IL.

Chen, H.T., Wang, C.Q. and Li, M.Y. (2006), "Numerical and experimental analysis of the $\mathrm{Sn} 3.5 \mathrm{Ag} 0.75 \mathrm{Cu}$ solder joint reliability under thermal cycling", Microelectronics Reliability, Vol. 46, pp. 1348-56.

Harris, P.G. and Chaggar, K.S. (1998), "The role of intermetallic compounds in lead-free soldering", Soldering E Surface Mount Technology, Vol. 10 No. 3, pp. 38-52.

Hwang, J.S. (2001), Environmental-Friendly Electronics: Lead-Free Technology, Electrochemical Publications, Isle of Man, p. 464.

Lee, N.C. (1999), "Optimizing the reflow profile via defect mechanism analysis”, Soldering $\mathcal{E}$ Surface Mount Technology, Vol. 11 No. 1, pp. 13-20.

Lee, N.C. (2002), Reflow Soldering Process and Troubleshooting: SMT, BGA, CSP, and Flip Chip Technologies, Newnes, Boston, MA.

Miric, A.Z. and Grusd, A. (1998), "Lead-free alloys", Soldering $\mathcal{E}$ Surface Mount Technology, Vol. 10 No. 1, pp. 19-25.

Oliver, J.R., Liu, J. and Lai, Z. (2002), "Effect of thermal ageing on the shear strength of lead-free solder joints", Proceedings of the IEEE International Symposium on Advanced Packaging Materials, Braselton, GA, pp. 152-6.

Pan, J., Toleno, B.J., Chou, T. and Dee, W.J. (2006), "The effect of reflow profile on $\mathrm{SnPb}$ and $\mathrm{SnAgCu}$ solder joint shear strength", Soldering \& Surface Mount Technology, Vol. 18 No. 4, pp. 48-56.

Roubaud, P. and Henshall, G. (2001), "Thermal fatigue resistance of $\mathrm{Pb}$-free second level interconnect", Proceedings of the SMTA International.

Salam, B., Virseda, C., Da, H., Ekere, N.N. and Durairaj, R. (2004), "Reflow profile study of the Sn-Ag-Cu solder", Soldering E Surface Mount Technology, Vol. 16 No. 1, pp. 27-34.

Webster, J., Pan, J. and Toleno, B.J. (2007), "Investigation of the lead-free solder joint shear performance", fournal of Microelectronic and Electronics Packaging, Vol. 4 No. 2, pp. 72-7.

Yang, W., Felton, L.E. and Messler, R.W. Jr (1995), "The effects of soldering process variables on the microstructure and mechanical properties of eutectic Sn/Ag solder joints”, Fournal of Electronic Materials, Vol. 24 No. 10, pp. 1465-72.

\section{About the authors}

Jianbiao Pan, $\mathrm{PhD}$, is an Associate Professor in the Department of Industrial and Manufacturing Engineering at California Polytechnic State University (Cal Poly), San Luis Obispo, California. He received his $\mathrm{BE}$ in Mechanics from Xidian University, Xian, China, in 1990, an MS in Manufacturing Engineering from Tsinghua University, Beijing, China, in 1996, and $\mathrm{ahD}$ in Industrial Engineering from Lehigh University,
Bethlehem, Pennsylvania, USA in 2000. He worked in the Optoelectronics Center at Lucent Technologies/Agere Systems as a member of technical staff before joining Cal Poly in 2003. His research interests include the materials, processes and reliability of microelectronics and optoelectronics packaging, lead-free solder joint reliability, LED packaging, and design and analysis of experiment. He is a senior member of IEEE, IMAPS and SME and a member of Sigma $\mathrm{Xi}$ and ASEE. He is a recipient of the 2004 M. Eugene Merchant Outstanding Young Manufacturing Engineer Award from the Society of Manufacturing Engineers (SME). He is a Highly Commended Winner of the Emerald Literati Network Awards for Excellence 2007. He is also an invitee of the National Academy of Engineering Frontiers in Engineering Symposium in 2007. Jianbiao Pan is the corresponding author and can be contacted at: pan@calpoly.edu

Tzu-Chien Chou is a Printed Circuit Board (PCB) Quality Engineer with IBM Integrated Supply Chain Group in Taiwan. $\mathrm{He}$ is responsible for PCB supplier manufacturing quality as well as raw card application engineering in server products. He received his MS degree in Industrial Engineering from Cal Poly, San Luis Obispo, California, in 2006. He worked at Solectron's Process technology Group, Milpitas, California, mainly focusing on RoHS/WEEE activities and lead-free solder joint reliability test in 2005-2006.

Jasbir Bath is the owner of Bath Technical Consultancy which provides consulting and training services in the electronics manufacturing industry. $\mathrm{He}$ is currently a Consulting Engineer for Christopher Associates/Koki Solder in the Americas and an INEMI Consultant working on the INEMI lead-free rework optimization project. He was the Corporate Lead Engineer with Solectron Corporation and Flextronics International for ten years with a role involving tin-lead and lead-free solder process development.

Dennis Willie is currently with Flextronics International, San Jose, California. $\mathrm{He}$ is 23 year veteran within the Contract Electronics Manufacturing business including 12 years at Elexsys/Sanmina as a Quality and Engineering Manager and 11 years at Solectron/Flextronics as an Engineering Manager for Analytical Lab Services, Backplane Assembly Business and Member of the Technology Leadership Group. Dennis received a Bachelor of Science degree in Business Management and Quality Systems from the University of Phoenix.

Brian J. Toleno, PhD, is a Director of Technical Service with Henkel in Irvine, California. Brian obtained a $\mathrm{PhD}$ in analytical chemistry from Penn State University and his BS in chemistry from Ursinus College. Prior to working at Henkel, he managed the failure analysis laboratory at the Electronics Manufacturing Productivity Facility. $\mathrm{He}$ is an active member of SMTA, served as the Program Chair for the 2005 IEMT and is active within the IPC serving as the underfill handbook committee (J-STD-030) chairperson and co-chairs the Solder Paste Standards Committee (J-STD-005). He has written a course on failure analysis for SMTA and has authored many publications for trade journals and peer reviewed publications, and two chapters for electronic engineering handbooks on adhesives and materials. 